\title{
Assessment of Vascular Permeability Increase in the Mouse by Dye Leakage during Paw Edema
}

\author{
Xiao Fei QUः, Masahiko HAYASHI, Kohji YAMAKI and Sachiko OH-ISHI* \\ Department of Pharmacology. School of Pharmaceutical Sciences. \\ Kitasato University. Minato-ku. Tokyo 108. Japan
}

Accepted December 29, 1989

\begin{abstract}
Vascular permeability increase induced by histamine, bradykinin, plateletactivating factor (PAF), or phorbol myristate acetate (PMA) in the mouse paw was assessed by the dye leakage method. The amount of dye extracted from the paw showed a clear dose-response relationship to the dose of each agonist injected into the paw. Among the autacoids used. PAF showed the most potent activity in the mouse paw. The results are consistent with those seen in the rat dorsal skin as previously reported. Involvement of histamine. 5-hydroxytryptamine and PAF is suggested in the vascular permeability increase induced by PMA in the mouse paw.
\end{abstract}

In acute inflammatory reactions, plasma exudation at the inflammatory site is an important parameter for evaluating the size and nature of the inflammatory reaction (1). To assess vascular permeability increases, we have measured the amount of dye leaked at the inflammatory site (2, 3) We found that there was significant species difference in the sensitivity of the vascular permeability increase induced by several autacoids (3). Since the mouse is commonly used as an experimental animal, we intend to develop a method to evaluate vascular permeability increases in mouse skin. Because the dorsal or abdominal skin of mice is too thin to examine dye leakage by the previous method, we therefore utilized the whole paw for this purpose.

Male 5-week-old ICR mice (Shizuoka Laboratory Animal Center, Hamamatsu) were kept in an air-conditioned room for one week before use. The mice were injected with 60 $\mathrm{mg} / \mathrm{kg}$ pontamine sky blue (Tokyo Kasei) in saline solution into a tail vein under light pentobarbital sodium anesthesia (Sigma;

* On leave from Shenyang College of Pharmacy. People's Republic of China, and in the Exchange Program for Graduate Students between Kitasato University and Shenyang College of Pharmacy.

* To whom correspondence should be addressed.
$50 \mathrm{mg} / \mathrm{kg}$, intraperitoneally). Ten minutes later. paw edema was induced by subcutaneous injection of $0.05 \mathrm{ml}$ of Tyrode solution containing the indicated dose of each agonist into the right paw, and $0.05 \mathrm{ml}$ of Tyrode solution alone was injected into the left paw as a control. In cases of platelet activating factor and phorbol myristate acetate. the vehicle contained final concentrations of $0.005 \%$ ethanol or $0.16 \%$ dimethylsulfoxide. Therefore, the vehicle was injected into the corresponding control paw. Mice were under the light anesthesia throughout the experiment and were exsanguinated to death 50 $\min$ after the agonist injection. Both paws were removed, and each paw was dipped in 1 $\mathrm{ml}$ of $1 \mathrm{~N} \mathrm{KOH}$ in a glass tube and kept overnight at $37^{\circ} \mathrm{C}$. The solution was neutralized with $2.5 \mathrm{ml}$ of $0.6 \mathrm{~N}$ phosphoric acid. and the dye was extracted with $6.5 \mathrm{ml}$ of acetone as previously reported (2). Absorbance at 620 $\mathrm{nm}$ was measured, and the amount of dye leakage was calculated by subtraction of the amount found in the control paw extract from that found in the extract of the agonistinjected paw. The mean dye amount extracted from each control paw injected with Tyrode solution was $12.1 \mu \mathrm{g} /$ paw with a standard error of $1.1(n=10)$. There was no significant difference among those that received the vehicles used. 
Figure 1A illustrates the dose-response relationship of the vascular permeability increase, as assessed by dye leakage at the mouse paw. to the dose of histamine (histamine maleate, Sigma), bradykinin (Peptide Institute. Minoh), platelet-activating factor (C 16 $_{\text {-PAF, }}$ 1-0-hexadecyl-2-0-acetyl-snglycero-3-phosphocholine, Bachem Finechemicals, Switzerland), or phorbol myristate acetate (PMA, Sigma). In this model. $\mathrm{C}_{16}$-PAF showed the most potent activity followed by bradykinin and then histamine: and this order of potency is similar to that seen previously in rat dorsal skin (3). Dye leakage caused by the above agonists had a short time course and mostly ended within $40 \mathrm{~min}$. Therefore, we terminated the reaction at 50 $\min$.

In the mouse paw. PAF (0.03 nmol) caused only additive dye leakage when injected simultaneously with histamine $(14 \mathrm{nmol})$ or bradykinin $(0.3 \mathrm{nmol})$, as shown in Fig. $1 \mathrm{~B}$ (inset). A similar result was obtained when the dose of PAF was reduced to $0.01 \mathrm{nmol}$ (data not shown). This result is different from that obtained in rat dorsal skin, where PAF induced synergistic dye leakage with bradykinin or histamine (3).

Effects of some inhibitors on PMA-induced paw edema were also examined. Indomethacin (Sigma, $10 \mathrm{mg} / \mathrm{kg}$ ) injected intraperitoneally $30 \mathrm{~min}$ before the agonist injection did not show any effect. Methysergide maleinate (a gift from Sandoz) injected intraperitoneally at the dose of $5 \mathrm{mg} / \mathrm{kg} 30 \mathrm{~min}$ before the PMA injection caused a significant inhibition of the dye leakage by $44.5 \pm 8.4 \%(n=7)$. As shown in Table 1, mepyramine (mepyramine maleate, Sigma) at a dose of $5 \mathrm{mg} / \mathrm{kg}$, significantly inhibited the dye leakage induced by 0.1 and by $1 \mathrm{nmol}$ of PMA. The specific PAF antagonist $\mathrm{CV}-3988$ (rac-3-(N-n-octadecylcarbamoyloxy) - 2 - methoxy-propyl - 2 - thiazolioethyl phosphate, a gift from Takeda Pharmac. Ind.) (4), when injected intravenously at the dose of $10 \mathrm{mg} / \mathrm{kg} 5 \mathrm{~min}$ before the agonist, significantly inhibited the dye leakage induced by $1 \mathrm{nmol} P M A$, but not that by $0.1 \mathrm{nmol}$ PMA (Table 1). CV-3988 either did not inhibit the dye leakage caused by

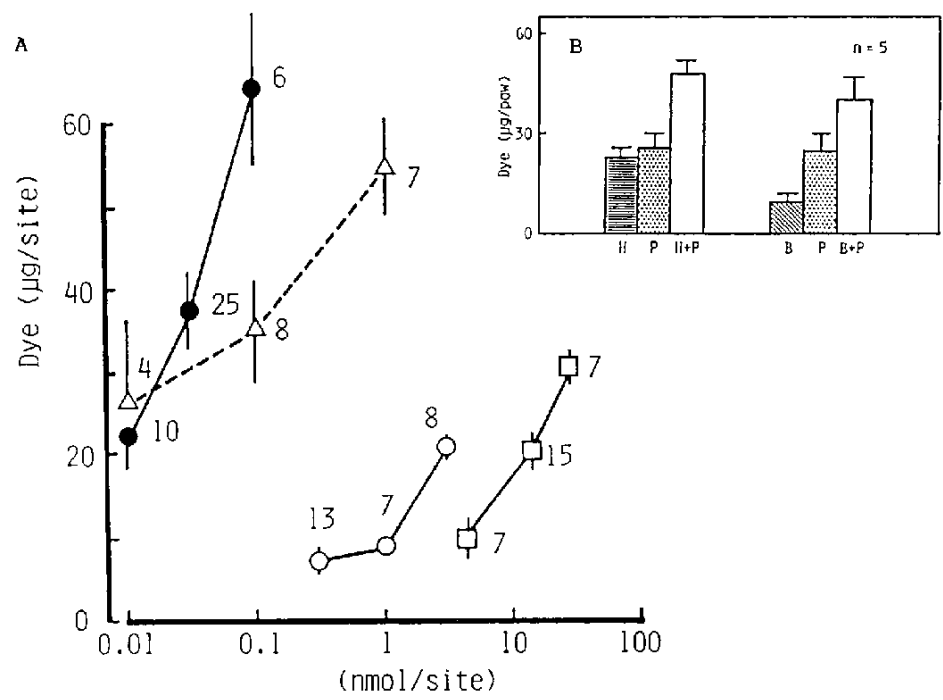

Fig. 1. Dye leakage in the mouse paw. $\triangle$. Relationship between the extracted dye amount and doses

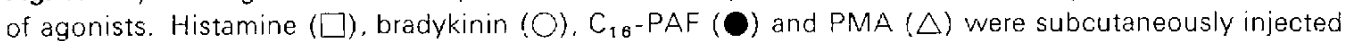
into mouse paw as described in the text. Figures by the symbols indicate numbers of mice used, and standard errors were expressed with bars. B (inset). Dye leakage in the mouse paw induced by bradykinin, histamine, $C_{16}$-PAF or their mixture. Histamine $(H, 14$ nmol), bradykinin ( $\mathrm{B}, 0.3$ nmol), $C_{16}$-PAF (P, 0.03 nmol), histamine $+C_{16}$-PAF $(H+P)$ or bradykinin $+C_{16}$-PAF $(B+P)$ was injected into the mouse paw as described in the text. The number of mice used was 5 for each group with standard error. 
Tabie 1. Effect of some inhibitors on PMA-induced dye leakage into the mouse paw

\begin{tabular}{|c|c|c|}
\hline Treatment & Number of mice & Dye ( $\mu \mathrm{g} /$ paw) \\
\hline \multicolumn{3}{|l|}{ PMA $(0.1 \mathrm{nmol} / \mathrm{site})$} \\
\hline No treatment & 6 & $37.1 \pm 5.9$ \\
\hline Mepyramine $(5 \mathrm{mg} / \mathrm{kg}$ ) & 4 & $8.8 \pm 0.4^{* *}$ \\
\hline CV $-3988(10 \mathrm{mg} / \mathrm{kg})$ & 6 & $52.8 \pm 4.2$ \\
\hline Mepyramine+CV-3988 & 4 & $8.3 \pm 2.2^{* *}$ \\
\hline \multicolumn{3}{|l|}{ PMA (1 nmol/site) } \\
\hline No treatment & 4 & $75.2 \pm 7.2$ \\
\hline Mepyramine $(5 \mathrm{mg} / \mathrm{kg}$ ) & 5 & $26.5 \pm 8.8^{* *}$ \\
\hline CV $-3988(10 \mathrm{mg} / \mathrm{kg})$ & 5 & $37.7 \pm 10.6^{*}$ \\
\hline Mepyramine+CV-3988 & 5 & $15.4 \pm 6.1^{* *}$ \\
\hline \multicolumn{3}{|l|}{ PAF (0.1 nmol/site) } \\
\hline No treatment & 6 & $66.4 \pm 6.8$ \\
\hline CV $-3988(10 \mathrm{mg} / \mathrm{kg})$ & 4 & $19.8 \pm 3.0^{* *}$ \\
\hline
\end{tabular}

Values express means with standard errors. Mepyramine was intraperitoneally injected 30 min before and $C V-3988$. intravenously 5 min before, PMA or PAF injection. "P<0.05 and ** $P<0.01$ indicate the value is significantly different from that of each non-treated group by Student's $t$-test.

bradykinin or histamine (data not shown).

These results indicate that the PMAinduced vascular permeability increase in mouse skin is probably mediated mainly by histamine and serotonin, and at higher doses. by PAF in addition to these autacoids. Simultaneous treatment with mepyramine and $\mathrm{CV}$ 3988 suppressed the $1 \mathrm{nmol}$ PMA-induced dye leakage, and this effect appeared to be additive effect as shown in Table 1, although the difference was statistically significant only between the control and each treated group. i.e., mepyramine, $\mathrm{CV}-3988$, or mepyramine$\mathrm{CV}$-3988, but not between mepyramine-CV3988 and each single treatment. In a previous study, we found that PMA induced mast cell degradation and release of histamine when injected into the rat pleural cavity (5) and that PMA also released PAF from resident mononuclear cells to cause plasma leakage into the pleural cavity (6). The above results with mouse paw are mostly consistent with the previous observations in rats.

There are some reports on the assessment of mouse paw edema induced by carrageenin by measurement of paw thickness (7) and of mouse ear edema by measurement of thickness after irritant application (8). The dye leakage method in the mouse paw is a convenient one for evaluating acute vascular leakage, especially in cases where paw swel- ling in the mouse induced by some autacoids is too small to be measured by volume change or thickness. On the other hand, in the case of carrageenin-induced inflammation in the paw. the measurement of thickness may be superior to the dye leakage method, since carrageenin edema takes a longer time to develop.

\section{References}

1 Van Arman, C.G.: Oedema and increased vascular permeability. In Anti-Inflammatory Drugs, Edited by Vane, J.R. and Ferreira. S.H., p. 73-91, Springer, Berlin (1979)

2 Oh-ishi, S., Tanaka, K., Katori, M., Han, Y.N., Kato, $H$. and Iwanaga, S.: Further studies on biological activities of new peptide fragments derived from high molecular weight kininogen: An enhancement of the vascular permeability increase of the fragments by prostaglandin $E_{2}$. Life Sci. 20, 695-700 (1977)

3 Oh-ishi, S., Hayashi, M. and Yamaki, K: Inflammatory effects of acetylglycerylether phosphorylcholine: Vascular permeability increase and induction of pleurisy in rats. Prostaglandins Leukotrienes Med. 22, 21-33 (1985)

4 Terashita, Z., Tsushima, S., Yoshioka, Y., Nomura, H., Inada, $Y$. and Nishikawa, K.: CV. 3988--a specific antagonist of platelet activating factor (PAF). Life Sci. 32, 1975-1982 (1983)

5 Kikuchi, $M$. and Oh-ishi, S.: Involvement of histamine in vascular permeability increase of rat pleurisy induced by phorbol myristate acetate. 
Japan. J. Pharmacol. 39, 467-473 (1985)

5 Hayashi, M., Kimura, J., Yamaki, K., Suwabe, Y., Dozen, M., Imai, Y. and Oh-ishi, S.: Detection of platelet-activating factor in exudates of rats with phorbol myristate acetate-induced pleurisy. Thromb. Res. 48, 299-310 (1987)

7 Halliday, W.J. and Webb, M.: Delayed hyper- sensitivity to chemically induced tumors in mice and correlation with an in vitro test. $\mathrm{JNCl} 43$. 141-149 (1969)

8 Asherson, G.L. and Ptak, W.: Contact and delayed hypersensitivity in the mouse. I. Active sensitization and passive transfer. Immunology 15. 405-416 (1968) 